\title{
Eaglesham Selected as 1994 Outstanding Young Investigator
}

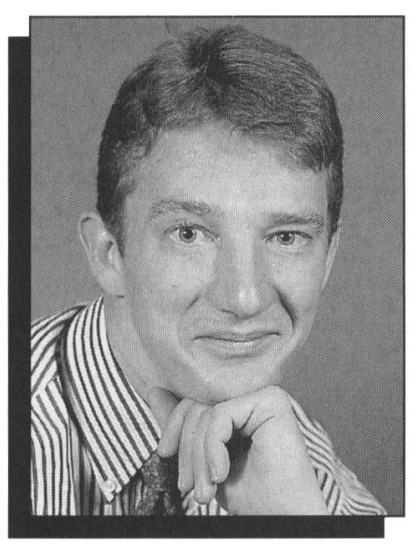

David J. Eaglesham is the 1994 recipient of the Materials Research Society's Outstanding Young Investigator Award. The Outstanding Young Investigator Award recognizes exceptional, interdisciplinary scientific work in materials research by a young scientist or engineer who also shows excellent promise as a developing leader in the materials area. A member of the technical staff at AT\&T Bell Laboratories, Murray Hill, New Jersey, Eaglesham is cited "for remarkable creativity, leadership, and experimental ingenuity in the discovery and understanding of fundamental interface, surface, and defect phenomena in semiconductor crystal growth."

Eaglesham is described as a person who aggressively pursues his ideas, is not afraid to take controversial views, and who supports his views by experiments. And, at age 32, Eaglesham has already demonstrated his potential as a researcher at AT\&T and a tenured professor at the University of Liverpool, and through graduate student research at the University of Bristol. He has well over 100 publications to his name.

He has gained rapid recognition and respect for innovative work combining transmission electron microscopy (TEM) and molecular beam epitaxy (MBE) to understand low-temperature silicon epitaxy and other phenomena involving surface energies and crystal growth. He opened up new dimensions in epitaxy and initiated a field of fundamental crystal growth studies around the world.

Eaglesham earned his BSc degree in chemical physics in 1982 and his PhD degree in 1985 in physics at the University of Bristol. His PhD research centered on the study of charge-densitywave phase transitions. These seminal studies demonstrated Eaglesham's outstanding experimental skills in developing TEM techniques for convergent beam diffraction analysis of structures and also in developing novel dark-field imaging and high-resolution studies.

As a lecturer in the Department of Materials Science at the University of Liverpool, his research shifted toward electronic and superconducting materials.
He made the first identification of a dislocation source in strained semiconductors, the $1 / 4$ [111] defect.

In 1988, he joined AT\&T Bell Laboratories, where he combined his electron microscopy skills with the investigation of epitaxial growth by MBE. He discovered the regime of silicon low-temperature epitaxy, and demonstrated that the defining parameter is epitaxial thickness, not temperature. He elucidated the link between epitaxy and growth conditions such as strain, roughness, and background contamination. Low-temperature growth permits electrical doping with concentration and dimensional constraints, which are important for new device technologies.

He has also done general investigations of semiconductor growth and morphology. He showed that the classic Stranski-Krastanov growth mode (layered growth then relaxed islands) involves a transition regime of strained islands which can be related to the elastic relaxation of strained islands.

The Materials Research Society's Outstanding Young Investigator Award will be presented to Eaglesham on Monday, April 4 during the 1994 MRS Spring Meeting in San Francisco. At noon on April 4, Eaglesham will give a presentation, "Low-Temperature Deposition of $\mathrm{Si}^{\text {," focusing on conditions }}$ that cause a deposited silicon film to be amorphous or crystalline.

\section{Finalists to Vie for Graduate Student Awards at 1994 MRS Spring Meeting}

MRS Graduate Student Awards are intended to honor and encourage graduate students whose academic achievements and current materials research display a high order of excellence and distinction. Twenty-two finalists, chosen from a growing pool of applicants, will make presentations describing their research during two special sessions at the 1994 MRS Spring Meeting. The special sessions are scheduled for Monday, April 4 , and everyone participating in the Spring Meeting is invited to attend. The finalists, their schools, and the symposia in which they are participating as authors or coauthors of a paper are as follows:

Wirote Boonkosum, Chulalongkorn

University, Thailand (A)

Dominique Coster, University of

Wisconsin-Milwaukee (N, V)

Peijun Ding, State University of
New York-Albany (B)

Steven R. Droes, University of

New Mexico (I)

Gretchen E. Fougere, Northwestern University (V)

Andrew Gabor, University of Colorado $(\mathrm{H})$

Paul Gee, University of CaliforniaLos Angeles (E)

Michael Glazov, University of Pennsylvania $(W)$

Jennifer Gray, University of Washington (E)

Neil C. Greenham, University of Cambridge, United Kingdom (L)

Parameswar Hari, University of Utah (A)

Andrew G. Johnston, University of Manchester, United Kingdom (K)

Cynthia R. Kachelmyer, University of Notre Dame (U)

Zhiyong Ma, University of Illinois-Urbana (B)

M.V. Ramona Murty, California Institute of Technology (W)
Tom Nolan, Stanford University $(\mathrm{H})$ Chenyu Pan, Rice University (T)

Suzette Keefe Pangrle, Pennsylvania

State University (N)

Yeon Soo Sung, University of

Wisconsin-Madison (S)

Steven J. Townsend, Cornell University $(\mathrm{H})$

Minh Q. Tran, University of Chicago (A)

Junzhong Zhang, Taiyuan University of

Technology, China (J)

The meeting registration fee is paid for all finalists, which also entitles them to MRS membership for a year. Each Award consist of a $\$ 250$ cash prize and a presentation plaque. The deadline for Graduate Student Award applications for the 1994 MRS Fall Meeting is August 26, 1994. For information, contact: Anne Wagner, Materials Research Society, 9800 McKnight Road, Pittsburgh, PA 15237-6006. Tel: (412) 367-3003; fax (412) 367-4373. 